\title{
Studies of inherent lubricity coatings for low surface roughness galvanised steel for automotive applications
}

Hill, Donal ; Holliman, Peter; McGetterick, James; Searle, Justin; Appelman, Marco; Chatterjee, Pranesh; Watson, Trystan M.; Worsley, David

\section{Lubrication Science}

DOI:

$10.1002 / \mathrm{ls} .1370$

Published: 01/08/2017

Peer reviewed version

Cyswllt i'r cyhoeddiad / Link to publication

Dyfyniad o'r fersiwn a gyhoeddwyd / Citation for published version (APA):

Hill, D., Holliman, P., McGetterick, J., Searle, J., Appelman, M., Chatterjee, P., Watson, T. M., \& Worsley, D. (2017). Studies of inherent lubricity coatings for low surface roughness galvanised steel for automotive applications. Lubrication Science, 29(5), 317-333.

https://doi.org/10.1002/ls.1370

\footnotetext{
Hawliau Cyffredinol / General rights

Copyright and moral rights for the publications made accessible in the public portal are retained by the authors and/or other copyright owners and it is a condition of accessing publications that users recognise and abide by the legal requirements associated with these rights. study or research

- Users may download and print one copy of any publication from the public portal for the purpose of private

- You may not further distribute the material or use it for any profit-making activity or commercial gain

- You may freely distribute the URL identifying the publication in the public portal?
}

Take down policy

If you believe that this document breaches copyright please contact us providing details, and we will remove access to the work immediately and investigate your claim. 


\title{
Studies of inherent lubricity coatings for low surface roughness galvanised steel for automotive applications
}

\author{
Donald Hill $^{1}$, Peter J. Holliman ${ }^{2, *, \dagger}$, James McGettrick ${ }^{1}$, Justin Searle ${ }^{1}$, \\ Marco Appelman ${ }^{3}$, Pranesh Chatterjee ${ }^{3}$, Trystan M. Watson ${ }^{1}$ and David Worsley ${ }^{1}$ \\ ${ }^{1}$ SPECIFIC, College of Engineering, Swansea University, Baglan, Port Talbot, Swansea, Wales SA12 7AX, UK \\ ${ }^{2}$ School of Chemistry, Bangor University, Bangor, Gwynedd LL57 2UW, UK \\ ${ }^{3}$ TATA Research \& Development, 1970 CA IJmuiden, The Netherlands
}

\begin{abstract}
Surface lubricity on $\mathrm{TiO}_{2}$ coated galvanised steels can be controlled by solution depositing perfluorooctanoic (C8), lauric (C12) or stearic (C18) acids to avoid lubricating oils/emulsions or substrate pre etching to remove surface oxide that add cost and waste. Water contact angles reveal increased surface hydrophobicity on coated samples that correlate with linear friction testing, suggesting water contact angle can be used to screen lubricity compounds. Linear friction testing shows that C12 and $\mathbf{C 1 8}$ lower the coef ficient of friction $(\mu)$ b y5 0 60\% compared with uncoated substrates whilst $\mathbf{C 8}$ drops $\mu$ from 0.31 to 0.22 . Surfaces have been characterised by X ray photoelectron spectroscopy, scanning electron microscopy and atomic force microscopy, whilst infrared confirms that as deposited coatings contain physisorbed and deprotonated acids chemisorbed through esters and thermal gravimetric analysis confirms increasing loadings from $\mathbf{C 8}$ to $\mathbf{C 1 2}$ to C18. Surface washing removes physisorbed material and lowers $\mu$ by increasing surface organisation and alkyl chain packing that enhances frictional energy dissipation through steric quenching. Copyright (C) 2017 John Wiley \& Sons, Ltd.
\end{abstract}

Received 29 July 2016; Revised 24 October 2016; Accepted 19 December 2016

KEY WORDS: lubricity; friction; sorption; automotive steel; sheet metal forming

\section{INTRODUCTION}

Galvanised steel is formed into complex shapes for vehicle bodies through techniques such as deep drawing that relies on material ductility to create new shapes as the substrate is forced over tools by the mechanical action of a punch. ${ }^{1,2}$ Adequate lubrication is essential to reduce friction to avoid wear on the substrate surface caused by frictional force at the interface between the substrate and the shaping tools. ${ }^{3}$ Currently, drawing oils, emulsions or colloids are deposited onto automotive steels by spray, roll or drip coating to act as deep drawing lubricants. ${ }^{4}$ Whilst these emulsions are non-toxic, they rely on the surface texture of the substrate to remain in place during forming. ${ }^{5}$ However, the poorer paint

*Correspondence to: Peter J. Holliman, School of Chemistry, Bangor University, Bangor, Gwynedd LL57 2UW, UK.

†E mail: p.j.holliman@bangor.ac.uk

Contract/grant sponsor: EPSRC EngD. 
finish, which can result from surface roughness, ${ }^{6}$ means the automotive sector is increasingly driving towards smoother substrates.

Consequently, there is a need to develop alternative lubricants that can operate at a wider range of surface texture specifications of automotive steels. Conformal deposition at a molecular level avoids macro-surface roughness issues because it operates at an entirely different length scale (pm compared with $\mu \mathrm{m}$ ). Previously, low surface energy monolayers have been used to generate low friction surfaces on different materials, e.g. stearate on $\mathrm{Al}^{7}$ or steel, ${ }^{8,9}$ silanes on $\mathrm{Si}^{10}$ or phosphonates on $\mathrm{Cu}^{11}$. In general, the organic molecules that form such monolayers contain linker groups that bind to substrate surface atoms and alkyl chains that orient away from the surface to reduce interfacial shear forces. ${ }^{12}$ However, prior reports for the surface functionalise metals or metal oxides have often used pretreatments such as polishing ${ }^{13}$ or plasma cleaning ${ }^{8}$ to generate homogeneous, ultra-clean and/or oxide-free surfaces. In a laboratory, these approaches work well but, on a production line, these extra steps increase cost and waste. Thus, we have taken the opposite approach and, rather than remove surface oxide, we have studied the self-assembly of carboxylic acids either onto precast $\mathrm{TiO}_{2}$ films or, where there is incomplete $\mathrm{TiO}_{2}$ surface coverage, directly onto the native $\mathrm{ZnO}$ surface layer of galvanised steel. We have chosen to use study the addition of a $\mathrm{TiO}_{2}$ layer onto the galvanised substrate because carboxylic acids have been observed to chemisorb as monolayers onto metal oxide surfaces (e.g. $\mathrm{TiO}_{2}$ ) through ester linkages ${ }^{14,15}$ in a similar way to that used in dye-sensitised solar cells. ${ }^{16,17}$

In this paper, we report studies of using stearic, lauric or perfluorooctanoic acid to generate costeffective, low toxicity, processable films with controlled surface lubricity on low surface roughness, galvanised automotive steel. Whilst low friction, stearate films have been reported on $\mathrm{Al}^{7}$, steel, ${ }^{8,9,13}$ and mica, ${ }^{19}$ to our knowledge, lauric and perfluorooctanoic acid have not been studied in this context. We have linked detailed characterisation of these surfaces with coefficient of friction $(\mu)$ and contact angle data. Whilst correlations between atomic force microscopy (AFM) friction coefficients and contact angle data have been reported for glass substrates, ${ }^{18}$ we also report the first attempts to determine whether such a correlation exists for galvanised steel substrates as such correlation would enable contact angle measurements to be used as screening methods for compounds that could imbue surface lubricity.

\section{MATERIALS AND METHODS}

\section{Samples and chemicals}

Galvanised steel (DX56, Tata Steel) was cut into $10 \times 20 \mathrm{~mm}^{2}$ coupons for characterisation and $50 \times 300 \mathrm{~mm}^{2}$ strips for linear fiction testing. The steel composition (wt\%) was $\mathrm{Al} 0.036, \mathrm{C} 0.0022$, Mo 0.001, Ni 0.001, N 0.0035, P 0.009, Si 0.003, S 0.010, Sn 0.004, Ti 0.050, V 0.002, Cr 0.012, $\mathrm{Cu} 0.026$, Mn 0.088 and B 0.002, and the balance was Fe. The surface roughness was $0.97 \pm 0.05$ $\mu \mathrm{m}$, measured using a Marsurf profilometer. All other chemicals were sourced from Sigma Aldrich and used without further purification.

\section{Surface functionalisation}

Samples were air dried after each of the following steps. Surface oil was removed from the steel by scrubbing with water and detergent and then ultra-sonicating in acetone for $5 \mathrm{~min}$. Selected 
substrates were immersed in an isopropanolic solution of $\mathrm{Ti}(\mathrm{OPr})_{4}(10 \mathrm{mM})$ for $30 \mathrm{~s}$. Substrates were then immersed in $100 \mathrm{mM}$ isopropanolic solutions of the carboxylic acids for $30 \mathrm{~s}$ before analysis. Selected samples were then either rinsed with acetone for 2 min or immersed in $100 \mathrm{mM} \mathrm{NaOH}_{(\mathrm{aq})}$ for $30 \mathrm{~s}$.

\section{Characterisation}

Contact angle measurements ( $n=5,5 \mu$ deionized water) were made using the sessile drop technique with a USB 2.0 camera and goniometer, and the data were fitted using FTA 32 software (FTA 32 Europe). Infrared (IR) spectra (4 scans, $4 \mathrm{~cm}{ }^{1}$ resolution) were recorded on a Perkin Elmer 100 Series attenuated total reflection Fourier transform infrared spectroscopy spectrometer, between 650 and $4000 \mathrm{~cm}^{1}$. Field emission gun scanning electron microscopy (SEM) was carried out on a Hitachi $\mathrm{S} 4800$ at $1.0 \mathrm{kV}\left(J_{\text {emission }}=5 \mu \mathrm{A}\right.$ and working distance $\left.=11.5 \mathrm{~mm}\right)$. Energy-dispersive X-ray (EDX) spectra were recorded using a Silicon Drift X-Max EDX detector and INCA EDX software (Oxford Instruments, Abingdon, UK) at $15.0 \mathrm{kV}\left(J_{\text {emission }}=15 \mu \mathrm{A}\right.$, working distance $=17.0 \mathrm{~mm}$ and acquisition $=100 \mathrm{~s}$ ). AFM data were measured over $10 \times 10 \mu \mathrm{m}$ scan areas on a JPK Nanowizard $3 \mathrm{AFM}$ in contact mode using a Si tip (thickness $3 \mu \mathrm{m}$ and length $225 \mu \mathrm{m}$ ) with a force constant of $2.8 \mathrm{~N} \mathrm{~m}{ }^{1}$. The tip velocity was $20 \mu \mathrm{m} \mathrm{s}^{1}$ with a line rate of $0.5 \mathrm{~Hz}$. X-ray photoelectron spectra (XPS) were recorded on an Axis Supra XPS (Kratos Analytical) using a monochromated Al $\mathrm{K}_{\alpha}$ source and large area slot mode detector $(300 \times 800 \mu \mathrm{m}$ analysis area). Data were recorded using a charge neutraliser to limit differential charging, and binding energies were calibrated to the main hydrocarbon peak (BE 284.8 $\mathrm{eV})$. For each etch, a survey scan was recorded using a pass energy of $160 \mathrm{eV}$. Data were fitted using CASA software with Shirley backgrounds. A $0.1 \mathrm{eV}$ step size was used when recording the highresolution spectra and a pass energy of $20 \mathrm{eV}$. Thermal gravimetric analysis (TGA) data were recorded on a Pyris 1 TGA, heating from 25 to $550^{\circ} \mathrm{C}$ at $25^{\circ} \mathrm{C}$ min ${ }^{1}$ under $\mathrm{N}_{2}\left(20 \mathrm{ml} \mathrm{min}{ }^{1}\right)$. Coefficients of friction were measured using linear friction testing (LFT), a strip drawing test similar to that reported by Trzepiecinski et al. $^{20}$ at $2224^{\circ} \mathrm{C}$ and $3045 \% \mathrm{RH}$ (Figure S1). To do this, samples $(50 \times 300 \mathrm{~mm}$, $n=3$ ) were pulled between round and cylindrical tools, clamped together with a force of $5 \mathrm{kN}$, at 0.345 $\mathrm{mm} \mathrm{s}{ }^{1}$ for a track length of $60 \mathrm{~mm}$. This sliding speed is slower than that typically used in deep drawing but was used to invoke very high friction to cause much faster removal of the zinc layer. Otherwise, the tests would have required prohibitively very large amounts of material to study LFT. A new tool pair was used for each LFT test. The pulling force was measured and used to calculate the coefficient of friction $(\mu)$ by taking an average of the data between 40 and $50 \mathrm{~mm}$ along the track length (where the values for $\mu$ had typically reached a plateau and where there is no longer believed to be any contribution from static friction behaviour that might occur at approximately $<10 \mathrm{~mm}$ ) and using Equation (1). All LFT tests were carried out in triplicate with mean values quoted (errors quoted are standard deviations from the mean).

$$
\mu=\text { pulling force } /(2 \times \text { normal force })
$$

Wear was assessed using digital photographs of the wear tools and by confocal microscopy using a Nanofocus $\mu$ Surf Mobile on $2.1 \times 2.1 \mathrm{~mm}$ areas of steel samples at $20 \times$ magnification. The data were plotted using MOUNTAINS software, version 7.3. 


\section{RESULTS AND DISCUSSION}

\section{Lubricity compounds and substrate}

Lubricity compounds typically contain three main functionalities: a linker group to fix the compound to the substrate surface, a long (usually alkyl) chain that reduces surface energy and side groups attached to the long chain (Scheme 1a). In this work, three compounds have been studied all of which possess a carboxylic acid linker group. However, the compounds chosen vary in the length of alky chain and side groups they possess. Thus, perfluorooctanoic acid possesses only C F side groups and consists of an 8 carbon chain and is subsequently labelled here as C8. By comparison, lauric and stearic acid possess only $\mathrm{C} \mathrm{H}$ side groups but consist of 12 and 18 carbon chains and so are labelled here as $\mathbf{C 1 2}$ and C18, respectively. The substrate chosen for lubricity testing (DX56) is galvanised steel with low surface roughness, which is designed for use in the automotive sector. The DX56 surface consists of a galvanic coating weight of $5090 \mathrm{~g} \mathrm{~m}^{2}$ that corresponds to a thickness of approximately $913 \mu \mathrm{m}$ made up of $99.7 \mathrm{wt} \% \mathrm{Zn}$ and $0.3 \mathrm{wt} \%$ Al. Thus, the outer surface of the DX56 substrate is expected to consist of a thin layer of predominantly $\mathrm{ZnO}$.

\section{Infrared spectroscopy}

After removing surface oil from the DX56 substrate, the lubricity compounds have been deposited onto the steel by dip coating. IR data for C8-coated steel show a broad peak at approximately 3250 $\mathrm{cm}^{1}$ (Figure 1) that also appears in the spectrum of the neat acid (S2). This is ascribed to intermolecular H-bonding between the carboxylic acid moieties, suggesting there is physisorbed acid on the surface. However, the $v \mathrm{C}=\mathrm{O}$ of neat $\mathbf{C 8}$ is not observed at $1711 \mathrm{~cm}{ }^{1}$ in the coated sample. Instead, two bands are observed at 1727 and $1652 \mathrm{~cm}^{1}$ (Figure 1), which are assigned as $\mathrm{vC}=\mathrm{O}$ and the asymmetric $v \mathrm{CO}_{2}$ of the carboxylate linker of $\mathbf{C 8}$ bound to the oxide surface in the bridging coordination mode. ${ }^{21}$ Bands at 1430 and $1366 \mathrm{~cm}^{1}$ are assigned to the symmetric $v \mathrm{CO}_{2}$ of the bridging coordination mode and tentatively to the asymmetric $v \mathrm{CO}_{2}$ of carboxylates bound through monodentate coordination. ${ }^{21}$ Whilst this suggests multiple coordination modes for $\mathbf{C 8}$, no bands for the monodentate carboxylate symmetric stretching vibration are observed.

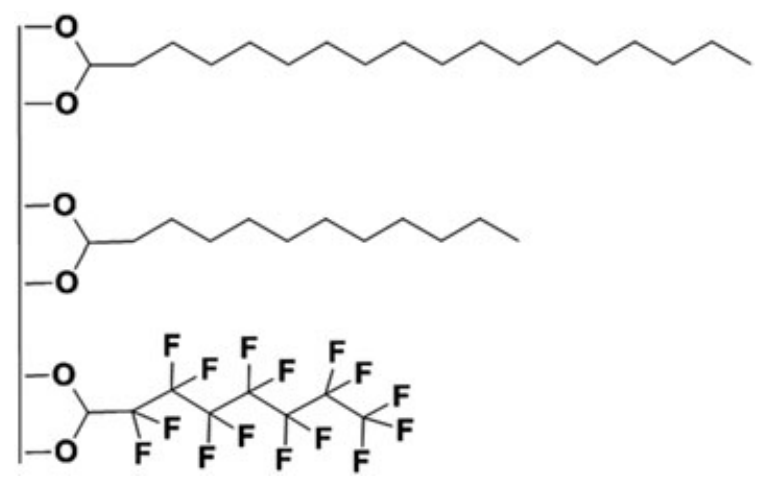

Scheme 1. Schematic of $\mathbf{C 1 8}$ (top), C12 (middle) or C8 (bottom) bound to surface sites in bridging coordination mode. $\mathrm{H}$ atoms omitted for clarity. 

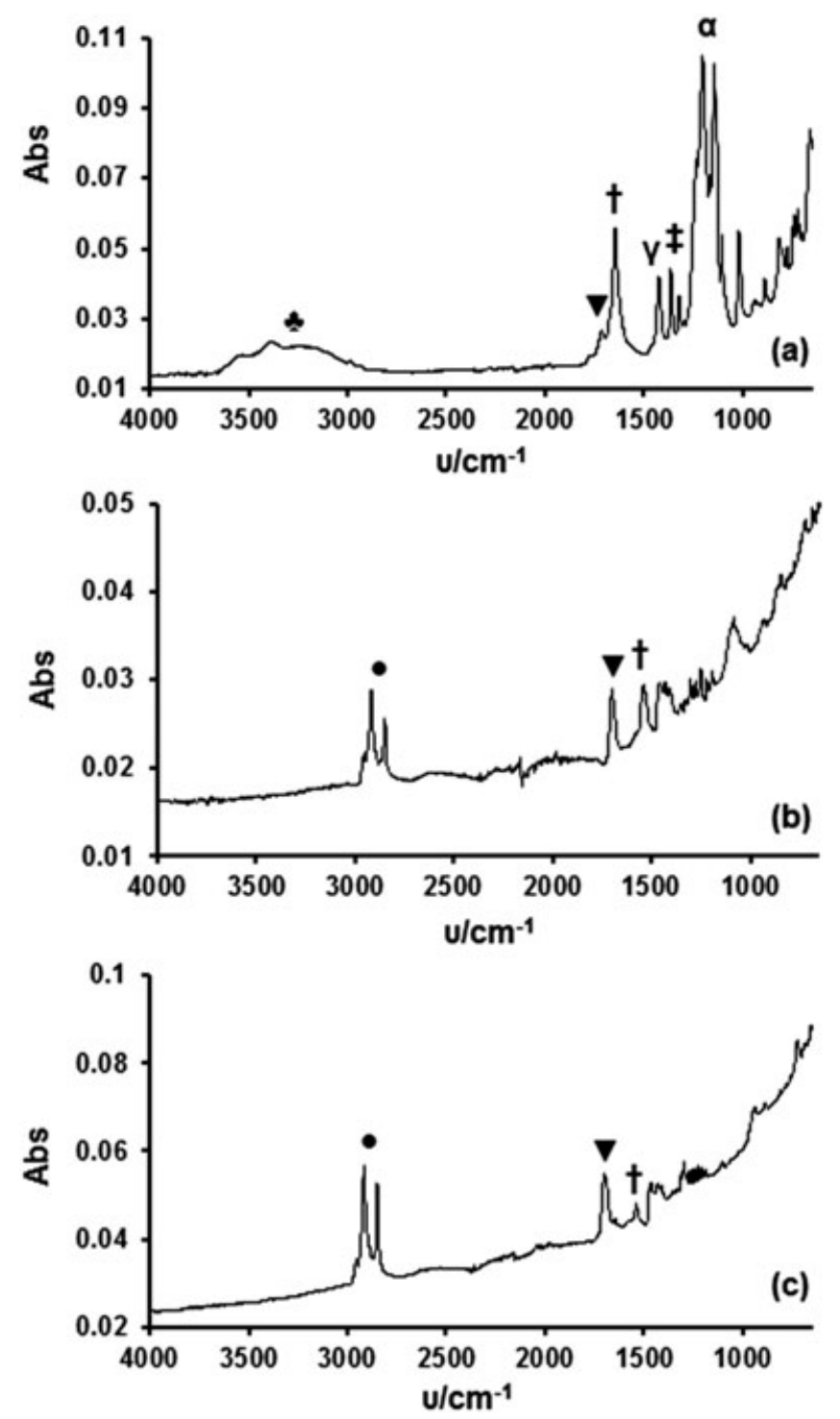

Figure 1. Infrared spectra of DX56 steel treated with (a) $\mathbf{C 8}$ (b) $\mathbf{C 1 2}$ or (c) $\mathbf{C 1 8} . \bullet, v \mathrm{C} \mathrm{H} ;, v \mathrm{O} \mathrm{H} ; \mathbf{\nabla}$, $v \mathrm{C}=\mathrm{O} ; \dagger, \nu \mathrm{CO}_{2}$ asym bridge; $\gamma, v \mathrm{CO}_{2}$ sym bridge $;$; $v \mathrm{CO}_{2}$ asym mon $; \alpha, v \mathrm{C} \mathrm{F}$.

Previous studies have shown that carboxylic acids can chemisorb to metal oxide surfaces through covalent ester bonds ${ }^{7,10,21}$ and that physisorbed molecules can be readily removed by solvent rinsing. ${ }^{7,8,22}$ To study this, acetone rinsing shows that, whilst no carbonyl or carboxylate stretching bands are observed, vC F are present between 1358 and $1140 \mathrm{~cm}^{1}$ (S3). This confirms that $\mathbf{C 8}$ remains adsorbed and suggests that the dipole moments of the carboxylate-related bands may be oscillating parallel to the surface and so are invisible in the IR spectrum. ${ }^{23}$ Further evidence for this is that, after 
$\mathrm{NaOH}_{(\mathrm{aq})}$ treatment to de-esterify the $\mathbf{C 8}$, there are no carboxylate or $\mathrm{C} \mathrm{F}$ bands in the spectrum confirming that all the remaining $\mathbf{C 8}$ has been desorbed (S4).

Infrared spectra for C12-coated and C18-coated DX56 show vC H at $30002800 \mathrm{~cm}^{1}$ (Figure 1). Both spectra show intense $v \mathrm{C}=\mathrm{O}$ bands at approximately $1700 \mathrm{~cm}^{1}$ and weaker carboxylate asymmetric $v \mathrm{CO}_{2}$ at approximately $1550 \mathrm{~cm}{ }^{1}$ whilst symmetric $v \mathrm{CO}_{2}$ bands are expected to be coincident with carboxylate-related bands from physisorbed $\mathbf{C 1 2}$ or C18. The signals observed are ascribed to non-dissociated $\mathbf{C 1 2}$ and $\mathbf{C 1 8}$ acids along with surface-bound esters, ${ }^{7,10,13}$ suggesting that both of these coatings contain physisorbed and chemisorbed $\mathbf{C 1 2}$ and C18, respectively. For both acetone rinsed coatings, symmetric and asymmetric $v \mathrm{CO}_{2}$ bands are observed at 1542 and $1400 \mathrm{~cm}{ }^{1}$, respectively along with a band ascribed to methylene scissoring at $1465 \mathrm{~cm}{ }^{124}$ (S3). These bands confirm that esterified, chemisorbed $\mathbf{C 1 2}$ and $\mathbf{C 1 8}$ remain on the surface whilst any physisorbed material is removed. Analysis of $\Delta v$ between $v \mathrm{CO}_{2}$ asym and $v \mathrm{CO}_{2}$ sym gives a value of approximately $140 \mathrm{~cm}^{1}$ for $\mathbf{C 1 2}$ and $\mathbf{C 1 8}$ coatings that is consistent with carboxylate groups coordinating to surface atoms in a bridging coordination mode. ${ }^{25}$ Such sorption has been observed in prior studies whereby bonding proceeds through coordination of both carboxylate oxygen atoms to two different surface sites. ${ }^{4,10,22}$ Scheme 1b shows bidentate coordination of $\mathbf{C 8}, \mathbf{C 1 2}$ and $\mathbf{C 1 8}$ on a substrate surface.

\section{Scanning electron microscopy}

Scanning electron microscopy for 'as received' DX56 steel shows contamination ascribed to oil deposited before transit to minimise corrosion. After cleaning, SEM confirms oil removal (S5a). After dip coating DX56 in $\mathrm{Ti}(\mathrm{OiPr})_{4}$ solution, the surface topography reduces due to the deposition of a $\mathrm{TiO}_{2}$ film whilst EDX data confirms Ti is present (S5b). For the lubricity compounds, the C8 surface shows few new features beyond the $\mathrm{TiO}_{2}$-coated DX56 although the surface appears darker, suggesting that the coating interacts differently with the electron beam (Figure 2a). The C12 surface shows more surface features, suggesting a thicker film has been deposited (Figure 2b), whilst the $\mathbf{C 1 8}$ surface shows needle-like structures (Figure 2c), suggesting stearic acid has deposited as a separate phase.

Atomic force microscopy data (S7) of $10 \times 10 \mu \mathrm{m}$ areas of the samples show low surface topography for the DX56 substrate $( \pm 10 \mathrm{~nm})$. After $\mathrm{Ti}(\mathrm{OPr})_{4}$ treatment, new features are observed, which are $200250 \mathrm{~nm}$ in height and which are ascribed to $\mathrm{TiO}_{2}$ particles that we observe in the SEM. After deposition of $\mathbf{C 8}$ (S8), a much higher surface topography is observed $( \pm 1000 \mathrm{~nm})$ but this drops to \pm 80 $\mathrm{nm}$ after rinsing in line with removal of some physisorbed $\mathbf{C 8}$. However, the surface topography is still much greater than the substrate, suggesting that a model similar to Figure $6 \mathrm{~d}$ is occurring for $\mathbf{C 8}$. For the $\mathbf{C 1 2}$ surface, the surface topography is $\pm 200 \mathrm{~nm}$ but this drops to $\pm 10 \mathrm{~nm}$ barring spikes for residual $\mathrm{TiO}_{2}$ particles (S9). However, the water contact angle (WCA) remains hydrophobic and the coefficient of friction remains low. This suggests monolayer $\mathbf{C 1 2}$ coverage represented in Figure $6 \mathrm{c}$. The as-deposited $\mathbf{C 1 8}$ surface shows angular particles with surface topography $\pm 80 \mathrm{~nm}$ (S10). XRD shows that these particles are crystalline indicating phase separation of excess stearate material (S11). After acetone rinsing, these particles disappear but the surface topography $( \pm 50 \mathrm{~nm})$ suggests multiple layers of $\mathbf{C 1 8}$ remain.

\section{$X$-ray photoelectron spectroscopy}

$\mathrm{X}$-ray photoelectron spectroscopy data for cleaned DX56 show Zn 2 $\mathrm{p}_{1 / 2}$ and $\mathrm{Zn} 2 \mathrm{p}_{3 / 2}$ photoelectron peaks at 1021.2 and $1044.0 \mathrm{eV}$, respectively, ${ }^{26-28}$ as well as a weak $\mathrm{Al} 2 \mathrm{p}$ photoelectron peak at $73.9 \mathrm{eV}$ (S12 and S13). This is expected as $\mathrm{Al}$ is added to the galvanic $\mathrm{Zn}$ coating to control the 

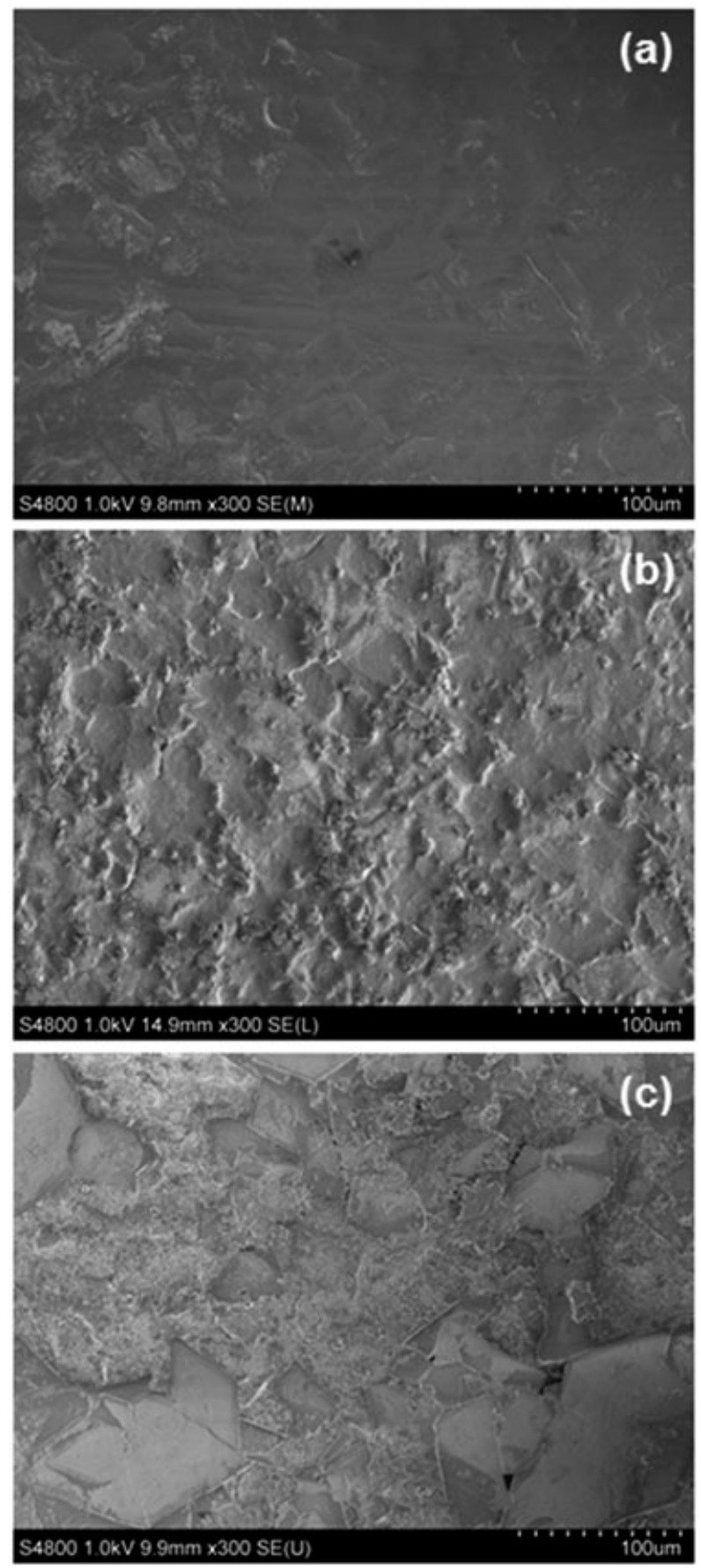

Figure 2. Scanning electron microscopy (SEM) data for $\mathrm{TiO}_{2}$ coated DX56 steel treated with (a) C8, (b) C12 or (c) C18. 
structure of the intermetallic formed at the interface between the $\mathrm{Zn}$ coating and the underlying steel. ${ }^{26}$ A broad $\mathrm{O} 1 \mathrm{~s}$ signal at $531.70 \mathrm{eV}$ also confirms the presence of surface oxide, ${ }^{26}$ mostly $\mathrm{ZnO}$ for the DX56 substrate. Figure 3 shows that, after Ti(OiPr $)_{4}$ treatment, Ti $2 \mathrm{p}_{1 / 2}$ and $\mathrm{Ti} 2 \mathrm{p}_{3 / 2}$ peaks are observed at 458.0 and $463.7 \mathrm{eV}$ in agreement with previous studies. ${ }^{29-31}$ The $\mathrm{O} 1 \mathrm{~s}$ signal also splits into two peaks at 531.2 and $529.5 \mathrm{eV}$ for $\mathrm{ZnO}$ and the newly formed $\mathrm{TiO}_{2}{ }^{32}$

$\mathrm{TiO}_{2}$-coated DX56 treated with $\mathbf{C 8}$ shows an intense $\mathrm{F} 1 \mathrm{~s}$ photoelectron peak at $689.9 \mathrm{eV}$ (S14) confirming the presence of fluorine on the surface. ${ }^{33}$ A C 1s peak centred at approximately 291.8 $\mathrm{eV}$ de-convolutes to reveal the presence of $\mathrm{C}=\mathrm{O}, \mathrm{CF}_{2}$, and $\mathrm{CF}_{3}$ moieties for the fluorinated carboxylic acid $^{34}$ (Figure 3). For the $\mathrm{TiO}_{2}$-coated DX56 treated with $\mathbf{C 1 2}$ or $\mathbf{C 1 8}$, the $\mathrm{C}$ 1s peak envelopes deconvolutes to reveal the presence $\mathrm{C}=\mathrm{O}, \mathrm{C} \mathrm{CO}_{2}$ and $\mathrm{C} \mathrm{C}$ components (Figure 3) as expected for these alkyl carboxylates. The assignments are in line with related studies for carboxylic acids binding to steel $^{13}$ or iron oxide surfaces. ${ }^{10}$

As a way to compare the loadings of $\mathbf{C 8}, \mathbf{C 1 2}$ and $\mathbf{C 1 8}$, the at $\%$ of $\mathrm{C} 1 \mathrm{~s}$ was found to be $31.6 \%$, $66.4 \%$ and $91.7 \%$, respectively. In this context, for typical photo-electron kinetic energies (10 1000 $\mathrm{eV}$ ), mean free path escape depths are $110 \mathrm{~nm}$ corresponding to 210 monolayers. ${ }^{35}$ Thus, the lower at\% of carbon and the higher intensity Zn 2p peaks for C8 (3.7 at $\%$ Zn) suggest either poor coverage with substantial surface area not occupied by $\mathbf{C 8}$ and/or a $\mathbf{C 8}$ loading of 12 monolayers. For C12, the at\% of $\mathrm{C}$ more than doubles whilst the $\mathrm{Zn}$ drops accordingly (1.2 at\% $\mathrm{Zn})$, suggesting either a higher coverage of $\mathbf{C 1 2}$ and/or a multilayer $\mathbf{C 1 2}$ loading. By comparison, the $\mathbf{C 1 8}$ coating shows the highest at $\%$ for $\mathrm{C}$ along with the lowest intensity $\mathrm{Zn} 2 \mathrm{p}$ peaks $(0.2$ at $\% \mathrm{Zn})$ that suggests almost complete coverage of $\mathbf{C 1 8}$ on the surface and/or a many multilayer loading of C18. To further understand loadings on $\mathrm{TiO}_{2}$ surfaces, C8, C12 or C18 were sorbed onto Degussa P25 powder and then TGA was measured to study the mass loss following their combustion (S15 and S-Table 1). From these data, the mass of C8, C12 or C18 initially sorbed onto P25 was found to be $10.9 \%, 71.0 \%$ and $78.8 \%$, respectively. After acetone washing, the sorbed masses of C8, C12 or C18 drop to $8.7 \%, 24.9 \%$ and $44.5 \%$, respectively. Whilst these data show very little change in the $\mathbf{C 8}$ loading after washing, the $\mathbf{C 1 2}$ loading drops by almost two-thirds and $\mathbf{C 1 8}$ drops by almost a half. These data correlate strongly with the IR data that lower peak intensities for the lubricity compounds $(\mathbf{C 8}, \mathbf{C 1 2}$ or $\mathbf{C 1 8})$ spectra after acetone washing.

Assuming $10 \mathrm{mg}$ of coated $\mathrm{P} 25 \mathrm{TiO}_{2}$, the acetone-washed loadings correspond to 2.1, 12.4 and 15.6 $\mu$ moles of C8, C12 or C18. Given that P25 has a surface area of approximately $50 \mathrm{~m}^{2} \mathrm{~g}{ }^{1,15}$ a $10 \mathrm{mg}$ sample has a surface area of $0.5 \mathrm{~m}^{2}$. The cross-sectional area of $\mathbf{C 1 8}$ has been reported to be $20.7 \AA^{2} .{ }^{36}$ Thus, to form a monolayer of $\mathbf{C 1 8}$ on $10 \mathrm{mg}$ of P25 should require $4.0 \mu$ mole of C18. Given that C8 and $\mathrm{C} 12$ both possess a similar carboxylate linkers to $\mathbf{C 1 8}$, it can be assumed that their cross-sectional areas should also be similar and thus should require similar loadings to achieve monolayer coverage. Thus, these data suggest an average of approximately 0.5, 3.0 and 4.0 monolayer coverage for $\mathbf{C 8}, \mathbf{C 1 2}$ and $\mathbf{C 1 8}$, respectively.

\section{Water contact angle measurements}

The WCA of 'as received' DX56 galvanised steel were highly variable, which is ascribed to surface oil used to reduce corrosion in transit. After thorough cleaning, DX56 displays a more consistent WCA $\left(55^{\circ} \pm 5^{\circ}\right)$ (Figure 4$)$. Whilst the WCA did not vary after $\mathrm{Ti}(\mathrm{OiPr})_{4}$ treatment, the addition of either $\mathrm{C12}$ or $\mathbf{C 1 8}$ generates hydrophobic surfaces with WCA of $88^{\circ} \pm 3^{\circ}$ and $110^{\circ} \pm 8^{\circ}$, respectively, suggesting these surfaces have been covered by the carboxylic acids. Similar WCA values have been 

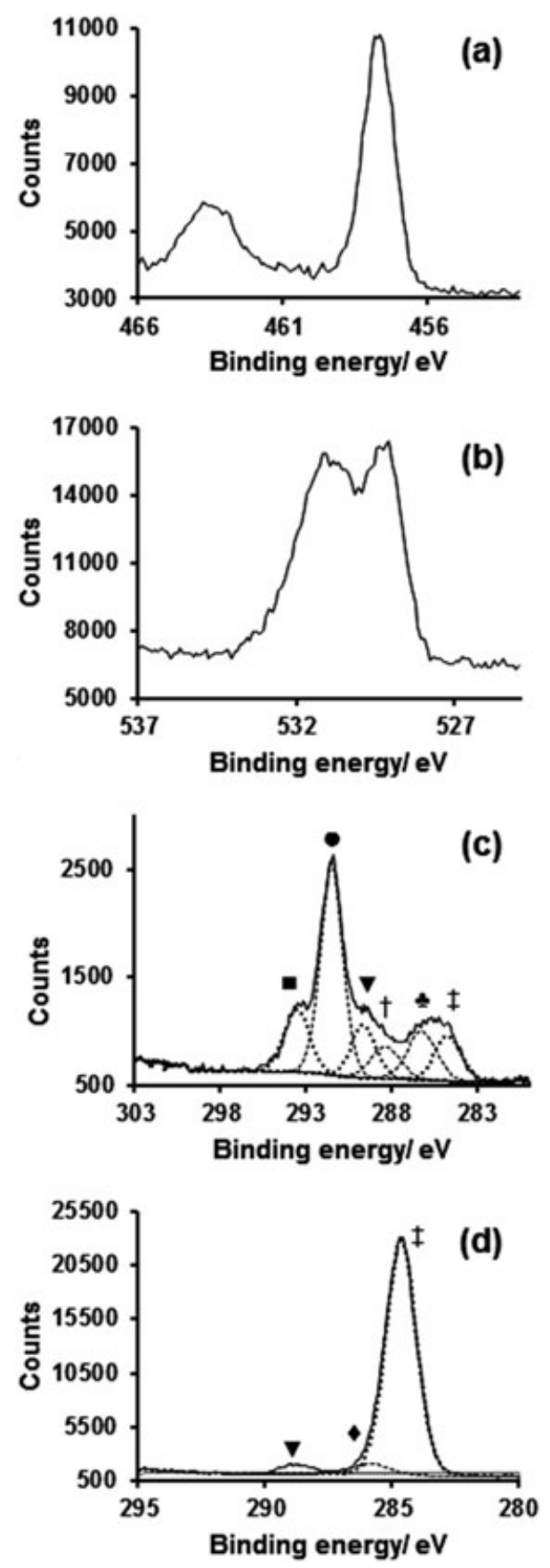

Figure 3. High resolution $\mathrm{X}$ ray photoelectron spectra of $\mathrm{TiO}_{2}$ coated DX56 substrate (a) Ti 2p and (b) O $1 \mathrm{~s}$ are regions. Other spectra show $\mathrm{C} 1 \mathrm{~s}$ regions after treatment with (c) $\mathbf{C 8}$ or (d) $\mathbf{C 1 2}$. $\mathbf{\nabla}, \mathrm{C}=\mathrm{O} ; \bullet, \mathrm{C} \mathrm{CO}_{2}$;






\section{HILL ET AL}


Figure 4. (a) Contact angles before (dark) and after (light) acetone rinsing and images for (b) $\mathrm{TiO}_{2}$ coated DX56 and $\mathrm{TiO}_{2}$ coated DX56 with (c) C8, (d) C12 and (e) C18.

reported for alkythiols on gold, ${ }^{37}$ alkylsilanes on paper ${ }^{38}$ and carboxylic acids on mica. ${ }^{39}$ By comparison, the equivalent $\mathbf{C 8}$ samples display hydrophilic WCA similar to the $\mathrm{TiO}_{2}$-coated and uncoated DX56 $\left(58^{\circ} \pm 7^{\circ}\right)$. This may be due to lower or less homogeneous $\mathbf{C 8}$ surface coverage or potentially the formation of a $\mathbf{C 8}$ bilayer whereby a second layer of $\mathbf{C 8}$ molecules orient their carboxylic acid groups away from the surface, increasing interaction with droplet water molecules (Figure 6d). However, the TGA data for $\mathbf{C 8}$ adsorbed onto $\mathrm{P} 25 \mathrm{TiO}_{2}$ show only 0.5 monolayer loading that suggests low coverage is the main reason for the low WCA value. To test this further, the WCA of acetone rinsed samples were also measured to ensure the removal of any physisorbed C8, C12 or C18. 
As expected, acetone rinsing did not affect the WCA of DX56 or $\mathrm{TiO}_{2}$-coated DX56. However, acetone rinsing C8-coated samples does increase WCA to $75^{\circ} \pm 6^{\circ}$, suggesting more of the surface consists of C F terminated chains. Similarly, the WCA of $\mathbf{C 1 2}$ increases to $108^{\circ} \pm 6^{\circ}$ in line with a more hydrophobic surface. In this case, removing physisorbed $\mathbf{C 1 2}$ increases the proportion of the surface that is C H alkyl terminated. Finally, rinsing C18-coated samples does not change the WCA, which suggests that, prior to rinsing, the surface was already alkyl terminated (Figure 6d).

\section{Linear friction testing}

Coefficients of friction $(\mu)$ have been determined using LFT that is an aggressive tribological test, during which the galvanised coating is completely removed (Figure 5a). Figure 5b shows how $\mu$ varies along the samples. Cleaned DX56 shows the highest friction during the first $10 \mathrm{~mm}(\mu>0.35)$, which then drops to between $\mu=0.220 .30$. The initial increased friction observed may be due to several reasons including stick-slip behaviour resulting from substantial differences in roughness across the substrate surface, running in behaviour being influenced by surface roughness, the presence of a built-up transfer layer or adhesive friction between the tool and substrate. The dynamic value of $\mu(0.23)$ for $\mathrm{TiO}_{2}$-coated DX56 suggests that adding $\mathrm{TiO}_{2}$ to the surface does not influence lubricity. For the coated samples, $\mu$ displays little variation along the samples and this absence of variable friction behaviour suggests that surface coverage is sufficiently homogeneous to overcome substrate surface roughness.

Interestingly, the $\mathbf{C 8}$ coating displays a dynamic $\mu$ of 0.20, which remains the same after acetone rinsing (Figure 5c). The high friction observed is in agreement with previous studies; high $\mu$ values have also been observed for perfluorinated carboxylic acids on silicon ${ }^{40}$ and for perfluorinated phosphonates on copper. ${ }^{11}$ High $\mu$ values have also been observed on related systems involving fluorinated ${ }^{41}$ or perfluorinated ${ }^{11,40}$ monolayers; discussions in the literature have attributed this to a number of factors including lower packing densities, relative to their hydrocarbon analogues, the molecular size of terminal groups and molecular disorder in the molecular films. ${ }^{42}$ By comparison, the $\mathbf{C 1 2}$ and C18 coatings give $\mu$ values of 0.11 and 0.10 (Figure 5c). This is in agreement with previously reported studies where large reductions in $\mu$ values have been reported for phosphonates on copper, ${ }^{11}$ silanes on silicon, ${ }^{10}$ and carboxylic acids on $\mathrm{Al}^{7}$ and steel, ${ }^{9}$ wherein it is believed that energy dissipation occurs through steric quenching between neighbouring alkyl chains. ${ }^{43}$ After acetone rinsing, the dynamic $\mu$ of C12 and C18 coatings remain the same, suggesting that sufficient chemisorbed material remains to imbue lubricity to these surfaces. Prior studies have shown that the stabilisation energy incurred through increasing the number $(n)$ of methylene $\left(\mathrm{CH}_{2}\right)$ groups in a chain saturates between $n=810{ }^{43}$

Analysis of the wear tools using digital photography (S16) shows that, after LFT testing, there is less build up of larger zinc flakes on the wear tools that had been used to test the $\mathbf{C 1 2}$ and $\mathbf{C 1 8}$ coatings compared with the uncoated FF substrate that is in agreement with the LFT data that these coatings reduce the coefficient of friction for these samples. Also, in line with the wear tool imaging and LFT data, confocal microscopy (S17) shows smaller scratches for the $\mathbf{C 1 2}$ and $\mathbf{C 1 8}$ coatings that suggests that less material has been removed and hence that the wear is lower for these coatings.

A plot of $\mu$ versus WCA (Figure 6a) shows that a negative correlation exists between the coefficient of friction and surface wettability. This suggests that it should be possible to predict substrate lubricity from contact angle data because, whilst WCA data only provide averaged information across the surface area of the water droplet used, these data do provide a measure of the extent of functionalisation of surfaces. This is key because it has been reported that close-packed monolayers can facilitate low friction behaviour on some surfaces by enabling energy dissipation by steric quenching between 
(a)
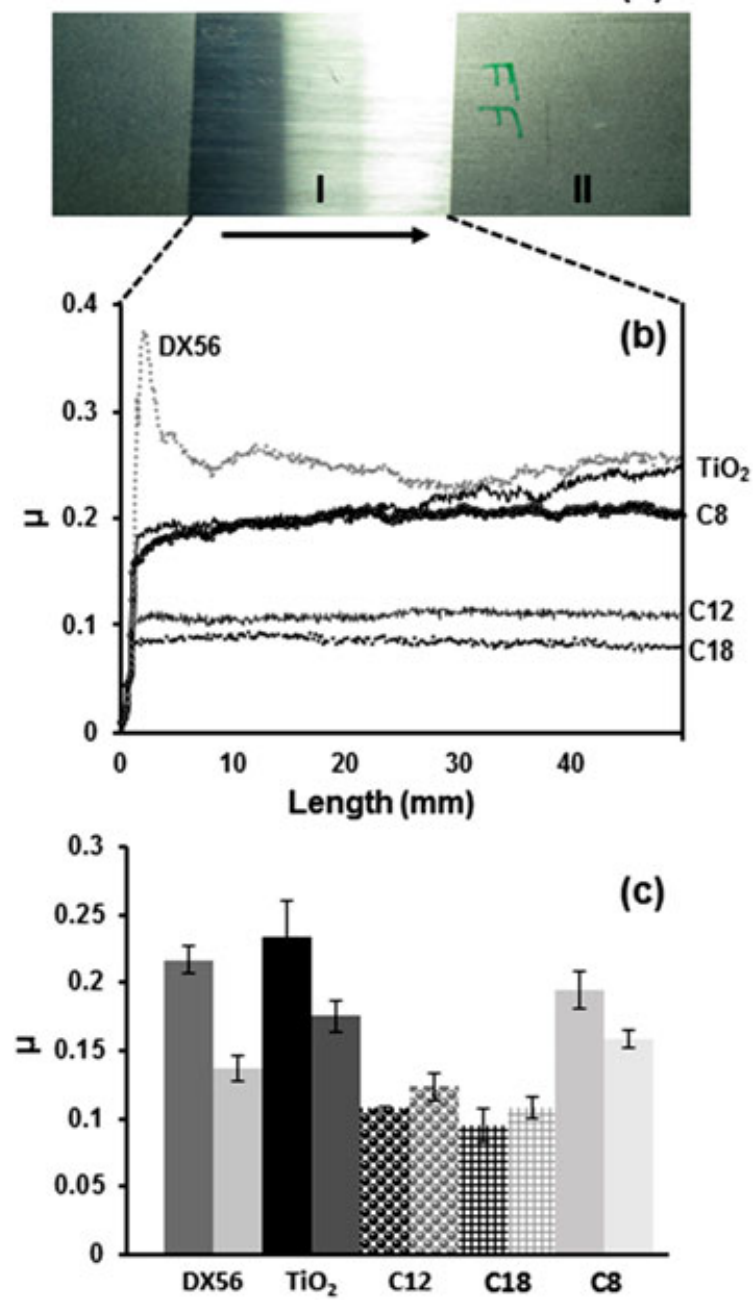

Figure 5. (a) Image of sample after linear friction testing, (b) dynamic coefficient of friction $(\mu)$ data and (c) mean $\mu$ for substrates before (dark shading) or after (light shading) acetone rinsing. DX56 steel (grey), $\mathrm{TiO}_{2}$ coated DX56 (black) and DX56 coated with C12 (circles), C18 (hashed) and C8 (light grey). [Colour figure can be viewed at wileyonlinelibrary.com]

neighbouring alkyl chains during tribological contact. ${ }^{43}$ Thus, whilst the correlation between WCA and $\mu$ effectively reflects surface coverage, the observed trend cannot take into account multiple layers and/or the molecular orientation within the surface films. However, with these provisos, our data do show that WCA can be used as a rapid screening method to identify substrate friction properties.

Applying this to our samples, for $\mathbf{C 8}$, this explains the high value of $\mu$ because the low surface coverage of $\mathbf{C 8}$ reduces intermolecular steric quenching, whilst uncoated areas possess no effective barrier during sliding (Figure 6c). By comparison, SEM and XPS data for the unrinsed $\mathbf{C 1 2}$ and $\mathbf{C 1 8}$ samples 


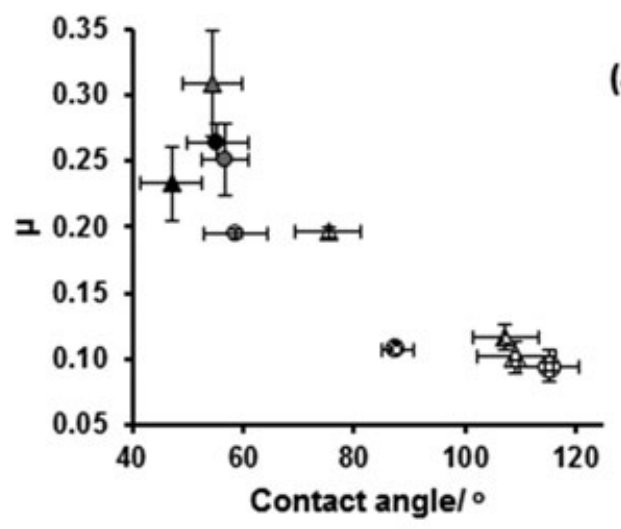

(a)

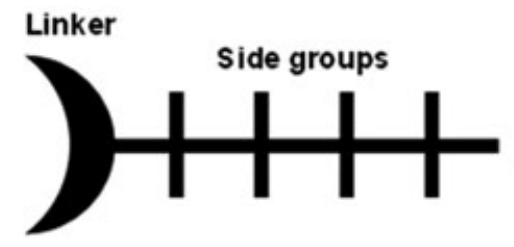

(b)

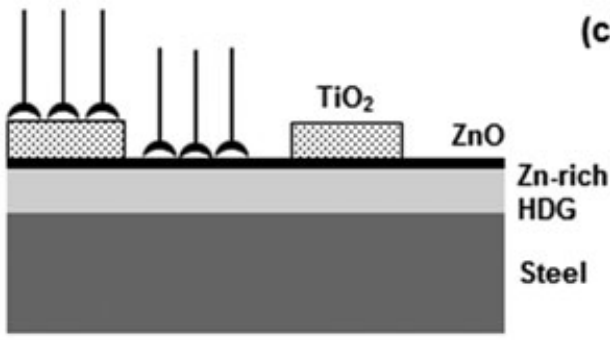

(c)

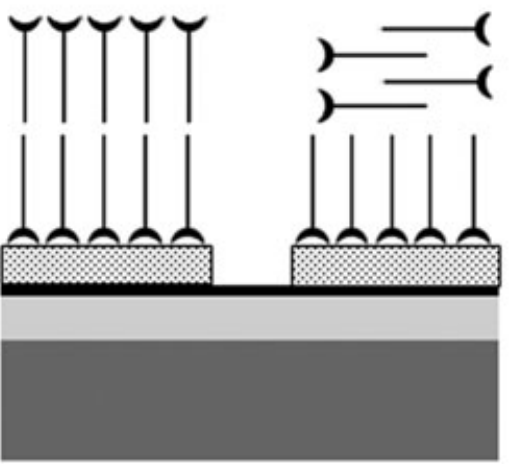

(d)

Figure 6. (a) Data for $\mu$ versus contact angle for DX56 steel (grey), $\mathrm{TiO}_{2}$ coated DX56 steel (black) and DX56 steel with $\mathbf{C 1 2}$ (dotted), C18 (hashed) and C8 (open). Circles are before acetone rinsing, and triangles are after acetone rinsing, (b) schematic of lubricity compound, and proposed models for (c) monolayer and (d) multilayer coatings of carboxylic acids on DX56 steel. 
show that the films are thicker than $\mathbf{C 8}$, show higher surface coverage and contain both physisorbed carboxylic acids and chemisorbed carboxylates (Figure $6 \mathrm{c}$ and $6 \mathrm{~d}$ ). Therefore, it is plausible to suggest that, prior to rinsing, the films act as more like barrier coatings, preventing interfacial contact between the substrate and tool during tribological contact. Interestingly, $\mu$ does not vary for these samples after solvent rinsing even through IR data shows that only chemisorbed carboxylates remain on the surface. This can be ascribed to the chemisorbed $\mathbf{C 1 2}$ and $\mathbf{C 1 8}$ carboxylates forming more ordered films where the alkyl chains are sufficiently ordered and close packed to enable steric quenching between neighbouring chains and thus to reduce frictional forces. This model for the structures of the coatings is shown (Figure $6 \mathrm{~b} 6 \mathrm{~d}$ ). This shows that the $\mathrm{TiO}_{2}$ layer formed as a result of dip coating process produces a partially covered surface. Between the $\mathrm{TiO}_{2}$-rich areas is $\mathrm{ZnO}$ from oxidation of the $\mathrm{Zn}$-rich galvanic layer. Where metal oxide is present, the carboxylic acids can then chemisorb through esterification to surface hydroxide groups to form a monolayer where the alkyl groups orient themselves away from the substrate surface. However, if the loading is high enough, additional layers can physisorb as shown in Figure 6d. Where free carboxylic acid groups orient themselves away from the substrate surface, it is possible for this to lower the WCA and increase $\mu$. Whilst solvent rinsing can remove this physisorbed material, only de-esterification using strong base can remove the chemisorbed species.

\section{CONCLUSIONS}

Controlling surface lubricity is key for reducing wear during metal forming. At the same time, reducing waste and improving surface finish are driving the need to avoid oil-based lubrication and to reduce the substrate surface roughness required for such emulsions to work. Our approach to these problems has been to develop films that imbue inherent lubricity to metal surfaces. Whilst previous reports have suggested this is possible by pre-etching the substrate to remove surface oxide, we have instead attached monolayers of oriented alkyl chains directly to the oxide surface through carboxylate linkers. This approach is both cost-effective and scaleable, and we have used it on substrates up to $30 \mathrm{~cm}$ in dimension. We have also screened different alkyl chain lengths and side groups ( $\mathrm{C} \mathrm{F}$ vs $\mathrm{C} \mathrm{H}$ ) and found that the initial deposits are thicker, multilayer films but that acetone washing removes physisorbed material for all the compounds tested. However, C12 (lauric acid) is the most effective in terms of monolayer coverage, WCA and coefficient of friction. By comparison, $\mathbf{C 8}$ (octanoic acid) shows low WCA and high $\mu$ whilst, for $\mathbf{C 1 8}$ (stearic acid), phase-separated particles of C18 are observed but, even after acetone rinsing, there is still too much material resulting in multilayer surface films. Whilst stearic acid is not expensive, this is still inefficient and wastes material. Through analysis of these data, it was also found that WCAs can act as an effective screening method for compounds that could increase the surface lubricity.

\section{ACKNOWLEDGEMENTS}

We gratefully acknowledge funding from EPSRC EngD and Tata Steel (D. H.), the Welsh Government for Sêr Cymru (P. J. H.) and EPSRC/Innovate UK EP/I019278/1 (J. Mc. and J. S.).

\section{REFERENCES}

1. Allen SJ, Mahdavian SM. The effect of lubrication on die expansion during the deep drawing of axisymmetrical steel cups. Journal of Materials Processing Technology 2008; 199:102 107. DOI:10.1016/j.jmatprotec.2007.08.005. 
2. Abe Y, Ohmi T, Mori K, Masuda T. Improvement of formability in deep drawing of ultra high strength steel sheets by coat ing of die. Journal of Materials Processing Technology 2014; 214:1838 1843. DOI:10.1016/j.jmatprotec.2014.03.023.

3. Stepina V, Vesely V. Lubricants and Special Fluids. Elsevier, Amsterdam 1992: 2.

4. Lascoe OD. Handbook of Fabrication Processes (5th edn). ASM Int. 1988: 264.

5. Oberg E, Jones FD, Horton HL, Ryffel HH. Machinery's Handbook (29th edn). Ind. Press, NY 2012: 1372.

6. Davies G. Materials for Automobile Bodies. Elsevier, Oxf. 2012: 113.

7. Zhang Q, Wan Y, Li Y, Yang S, Yao W. Friction reducing behavior of steric acid on a textured aluminum substrate. Applied Surface Science 2013; 280:545 549. DOI:10.1016/j.apsusc.2013.05.024.

8. Ruths M, Lundgren S, Danerlöv K, Persson K. Friction of fatty acids in nanometer sized contacts of different adhesive strength. Langmuir 2008; 24:1509 1516. DOI:10.1021/la7023633.

9. Loehlé S, Matta C, Minfray C, Le Mogne T, Iovine R, Obara Y, Miyamoto A, Martin JM. Mixed lubrication of steel by C18 fatty acids revisited. Part I: toward the formation of carboxylate. Tribology International 2015; 82:218 227. DOI:10.1016/j. triboint.2015.08.036.

10. De Palma V, Tillman N. Friction and wear of self assembled trichlorosilane monolayer films on silicon. Langmuir 1989; 5:868 872. DOI:10.1021/la00087a049.

11. Hoque E, DeRose JA, Bhushan B, Hipps KW. Low adhesion, non wetting phosphonate self assembled monolayer films formed on copper oxide surfaces. Ultramicroscopy 2009; 109:1015 1022. DOI:10.1016/j.ultramic.2009.03.033.

12. Liu H, Bhushan B. Investigation of nanotribological properties of self assembled monolayers with alkyl and biphenyl spacers. Ultramicroscopy 2002; 91:185 202. DOI:10.1016/S0304 3991(02)00099 2.

13. Sahoo RR, Biswas SK. Frictional response of fatty acids on steel. Journal of Colloid and Interface Science 2009; 333:707 718. DOI:10.1016/j.jcis.2009.01.046.

14. Holliman PJ, Vaca Velasco B, Butler I, Wijdekop M, Worsley D. Studies of dye sensitisation kinetics and sorption iso therms of Direct Red 23 on titania. International Journal of Photoenergy 2008:1 8. DOI:10.1155/2008/827605.

15. Charbonneau C, Holliman PJ, Davies M, Watson T, Worsley D. Facile self assembly and stabilization of metal oxide nano particles. Journal of Colloid and Interface Science 2015; 442:110 119. DOI:10.1016/j.jcis.2014.11.042.

16. Holliman PJ, Al Salihi KJ, Connell A, Davies ML, Jones EW, Worsley DA. Development of selective, ultra fast multiple co sensitization to control dye loading in dye sensitized solar cells. RSC Advances 2014; 4:2515 2522. DOI:10.1039/ c3ra42131g.

17. Connell A, Holliman PJ, Jones EW, Furnell L, Kershaw C, Davies ML, Gwenin CD, Pitak MB, Coles SJ, Cooke G. Mul tiple linker half squarylium dyes for dye sensitized solar cells; are two linkers better than one? Journal of Materials Chem istry A 2015; 3:2883 2894. DOI:10.1039/C4TA06896C.

18. Beake BD, Leggett GJ. Variation on frictional forces in air with the composition of heterogeneous organic surfaces. Lang muir 2000; 16:735 739. DOI:10.1021/la990782d.

19. Lundgren SM, Ruths M, Danerlöv K, Persson K. Effects of unsaturation on film structure and friction of fatty acids in a model base oil. Journal of Colloid and Interface Science 2008; 326:530 536. DOI:10.1016/j.jcis 2008.05.068.

20. Trzepiecinski T, Bazan A, Lemu HG. Frictional characteristics of steel sheets used in automotive industry. International Journal of Automotive Technology 2015; 16:849 863. DOI:10.1007/s12239 01500871.

21. Przedlacki M, Kajdas C. Tribochemistry of fluorinated fluids hydroxyl groups on steel and aluminum surfaces. Tribology Transactions 2006; 49:202 214. DOI:10.1080/05698190500544676.

22. Taheri P, Wielant J, Hauffman T, Flores JR, Hannour F, de Wit JHW, Mol JMC, Terryn H. A comparison of the interfacial bonding properties of carboxylic acid functional groups on zinc and iron substrates. Electrochimica Acta 2011; 56:1904 1911. DOI:10.1016/j.electacta.2010.10.079.

23. Greenler RG, Snider DR, Witt D, Sorbello RS. The metal surface selection rule for infrared spectra of molecules adsorbed on small metal particles. Surface Science 1982; 118:415 428. DOI:10.1016/0039 6028(82)90197 2.

24. Ozturk S, Balkose D, Okur S, Umemura J. Effect of humidity on electrical conductivity of zinc stearate nanofilms. Colloids and Surfaces A: Physicochemical and Engineering Aspects 2007; 302:67 74. DOI:10.1016/j.colsurfa.2007.01.039.

25. Kutscher JS, Gericke A, Húhnerfuss $\mathrm{H}$. Effect of bivalent $\mathrm{Ba}, \mathrm{Cu}, \mathrm{Ni}$ and $\mathrm{Zn}$ cations on the structure of octadecanoic acid monolayers at the air water interface as determined by external infrared reflection absorption spectroscopy. Langmuir 1996; 12:1027 1034. DOI:10.1021/la950731q.

26. Feliu S, Jr, Barranco V. XPS study of the surface chemistry of conventional hot dip galvanized pure Zn, galvanneal and the $\mathrm{Zn} \mathrm{Al} \mathrm{alloy} \mathrm{coatings} \mathrm{on} \mathrm{steel.} \mathrm{Acta} \mathrm{Materialia} \mathrm{2003;} \mathrm{51:5413} \mathrm{5424.} \mathrm{DOI:10.1016/S1359} \mathrm{6454(03)00408} 7$.

27. Lebrini M, Fontaine G, Gengembre L, Traisnel M, Lerasle O, Genet N. Corrosion behaviour of galvanized steel and electroplating steel in aqueous solution: AC impedance study and XPS. Applied Surface Science 2008; 254:6943 6947. DOI:10.1016/j.apsusc.2008.04.112. 
28. Arenas MA, García I, Damborenea J. X ray photoelectron spectroscopy study of the corrosion behaviour of galvanised steel implanted with rare earths. Corrosion Science 2004; 46:1033 1049. DOI:10.1016/S0010 938X(03)00193 8.

29. Pazokifard S, Farrokhpay S, Mirabedini M, Esfandeh M. Surface treatment of $\mathrm{TiO}_{2}$ nanoparticles via sol gel method: effect of silane type on the hydrophobicity of the nanoparticles. Progress in Organic Coatings 2015; 87:36 44. DOI:10.1016/j. porgcoat.2015.04.021.

30. Al Kandari H, Mohamed AM, Al Kharafi F, Katrib A. XPS UPS, ISS characterization studies and the effect of Pt and K addition on the catalytic properties of $\mathrm{MoO}_{2} \times(\mathrm{OH})_{\mathrm{y}}$ deposited on $\mathrm{TiO}_{2}$. Journal of Electron Spectroscopy and Related Phe nomena 2011; 184:472 478. DOI:10.1016/j.elspec.2011.07.001.

31. Kruse N, Chenakin S. XPS characterization of $\mathrm{Au} / \mathrm{TiO}_{2}$ catalysts: binding energy assessment and irradiation effects. Applied Catalysis A: General 2011; 391:367 376. DOI:10.1016/j.apcata.2010.05.039.

32. Hanawa T, Ota M. Calcium phosphate naturally formed on titanium in electrolyte solution. Biomater. $1991 ; 12: 767$ 774. DOI:10.1016/0142 9612(91)900289.

33. Beamson G, Briggs D, High resolution XPS of organic polymers: the Scienta ESCA300 Database, 1992.

34. Suzuki S, Whittaker MR, Wentrup Byrne E, Monterio MJ, Grondahl L. Adsorption of well defined fluorine containing polymers onto poly(tetrafluoroethylene). Langmuir 2008; 24:13075 13083. DOI:10.1021/la802300q.

35. Seah MP, Dench WA. Quantitative electron spectroscopy of surfaces: a standard database for electron inelastic mean free paths in solids. Surface and Interface Analysis 1979; 1:2 11. DOI:10.1002/sia.740010103.

36. Lane CL, Burton E, Crabb CC. Accurate molecular dimensions from stearic acid monolayers. J. Chem. Ed. 1984; 61:815. DOI:10.1021/ed061p815.

37. Nuzzo RG, Allara DL. Adsorption of bifunctional organic disulfides on gold surfaces. Journal of the American Chemical Society 1983; 105:4481 4483. DOI:10.1021/ja00351a063.

38. Oh MJ, Lee SY, Paik KH. Preparation of hydrophobic self assembled monolayers on paper surfaces with silanes. Journal of Industrial and Engineering Chemistry 2011; 17:149 153. DOI:10.1016/j.jiec.2010.12.014.

39. Sauthiera G, Segurac JJ, Fraxedasa J, Verdaguer A. Hydrophobic coatings of mica by stearic acid vapor deposition. Colloids Surf. A: Physicochem. Eng. Aspects 2014; 443:331 337. DOI:10.1016/j.colsurfa.2013.11.031.

40. Singh RA, Yoon ES, Han HG, Kong H. Friction behaviour of chemical vapor deposited self assembled monolayers on sil icon wafer. Wear 2007; 262:130 137. DOI:10.1016/j.wear.2006.04.001.

41. Kim HI, Graupe M, Oloba O, Koini T, Imaduddin S, Lee TR, Perry SS. Molecularly specific studies of the frictional prop erties of monolayer films: a systematic comparison of $\mathrm{CF}_{3},\left(\mathrm{CH}_{3}\right)_{2} \mathrm{CH}$, and $\mathrm{CH}_{3}$ terminated films. Langmuir 1999; 15:3179 3185. DOI:10.1021/la981497h.

42. Singh RA, Kim J, Yang SW, Oh JE, Yoon ES. Tribological properties of trichlorosilane based one and two component self assembled monolayers. Wear 2008; 265:42 48. DOI:10.1016/j.wear.2007.08.016.

43. Lio A, Charych DH, Salmeron M. Comparative atomic force microscopy study of the chain length dependence of frictional properties of alkanethiols on gold and alkylsilanes on mica. The Journal of Physical Chemistry B 1997; 101:3800 3805. DOI:10.1021/jp963918e.

\section{SUPPORTING INFORMATION}

Supporting information may be found in the online version of this article at the publisher's web site.

Fig. S1 LFT testing kit. Redrawn from T. Trzepiecinski, A. Bazan, H.G. Lemu, Int. J. Automotive Tech., 2015, 16, 849 .

Fig. S2 ATR-IR of neat (a) C8, (b) C12 and (c) C18

Fig. S3 ATR-IR spectra for (a) C8, (b) C12 or (c) C18 coated onto TiO2-coated DX56 steel surfaces after acetone rinsing

Fig. S4 ATR-IR of C8 treated TiO2-coated DX56 steel after desorption of C8 using NaOH(aq)

Fig. S5 Scanning electron microscopy (SEM) and energy dispersive X-ray spectroscopy (EDX) data for (a) DX56 steel after cleaning and (b) TiO2-coated DX56. All EDX spectra recorded using $15.0 \mathrm{kV}$ accelerating voltage.

Fig. S6 SEM and EDX data for (a) C8, (b) C12 and (c) C18 on TiO2-coated DX56 steel. All EDX 
spectra recorded using $15.0 \mathrm{kV}$ accelerating voltage.

Fig. S7 AFM images of (a) DX56 and (c) associated line scan, (b) titanium isopropoxide treated DX56 and (d) associated line scan.

Fig. S8 AFM images of (a) C8 surface and (c) associated line scan, (b) C8 surface after acetone rinsing and (d) associated line scan.

Fig. S9 AFM images of (a) C12 surface and (c) associated line scan, (b) C12 surface after acetone rinsing and (d) associated line scan.

Fig. S10 AFM images of (a) C18 surface and (c) associated line scan, (b) C18 surface after acetone rinsing and (d) associated line scan.

Fig. S11X-ray diffraction patterns of (a) DX56 steel substrate and (b) C18 deposited onto DX56 showing additional stearate signals at values of $2 \theta<13^{\circ}(\dagger)$

Fig. S12 Clockwise from left: Zn 2p, C 1s, O 1s, and Al 2p high resolution XPS data for cleaned DX56 steel

Fig. S13 (Clockwise from top left) XPS survey data of DX56 substrate, TiO2 coated-DX56 and C12, $\mathrm{C} 18$ and $\mathrm{C} 8$ deposited on $\mathrm{TiO} 2$ coated-DX56.

Fig. S14 F 1s high resolution XPS data for C8 coated on TiO2-coated DX56 steel.

Fig. S15 TGA of lubricity compounds (a) deposited onto P25 titania and (b) deposited onto P25 titania and then acetone washed. Data show C8 (blue line), C12 (green line) and C18 (brown line).

Fig. S16 Images of flat tools (a) before LFT testing and after LFT testing of (b) DX56 substrate, (c) $\mathrm{TiO} 2$ coated-DX56, (d) C8, (e) $\mathrm{C} 12$ and (f) $\mathrm{C} 18$ coatings

Fig. S17 Confocal images of DX56 substrate (a) before and (b) after contact with LFT flat tool, TiO2 coated-DX56 substrate (c) before and (d) after contact with LFT flat tool, C8 subsrtate (e) before and (f) after contact with LFT flat tool, C12 substrate (g) before and (h) after contact with LFT flat tool, and C18 substrate (i) before and (j) after contact with LFT flat tool.

Table. S1 Weight losses from TGA data for C8, C12 and C18 adsorbed onto P25 titania either before or after acetone washing. Standard deviations of $n=3$ replicates are shown in parentheses 